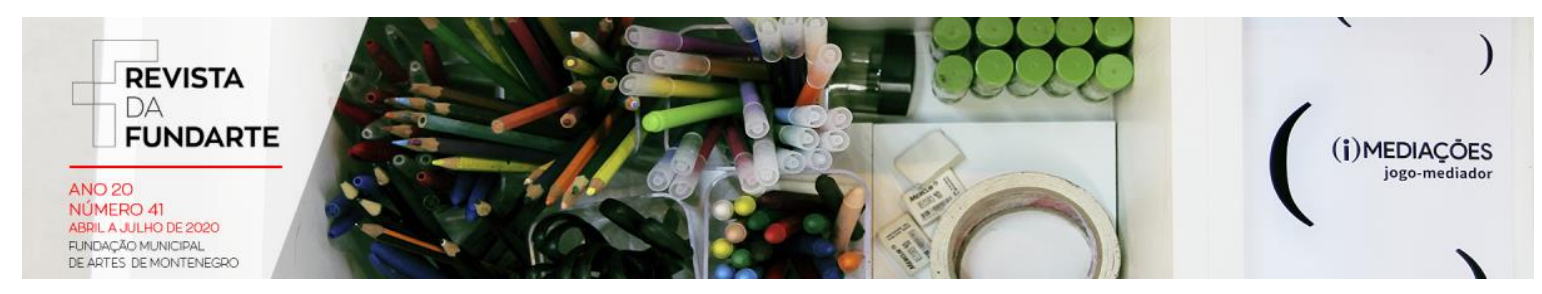

\title{
EDUCAÇÃO MUSICAL NO CONTEXTO DE JOVENS E ADULTOS COM DIVERSIDADE FUNCIONAL INTELECTUAL: RECURSOS DE APRECIAÇÃO MUSICAL
}

Edson Ribeiro Biondo Júnior

Diewerson do Nascimento Raymundo

DOI: http://dx.doi.org/10.19179/2F2319-0868/2F759

BIONDO JÚNIOR, Edson Ribeiro; RAYMUNDO, Diewerson do Nascimento. Educação Musical no contexto de jovens e adultos com diversidade funcional intelectual: recursos de Apreciação Musical. Revista da FUNDARTE. Montenegro, p.01-21, ano 20, oㅡ 41, Abril/Junho de 2019.

Disponível em: http://.seer.fundarte.rs.gov.br/index.php/RevistadaFundarte/index> 30 de junho de 2020. 


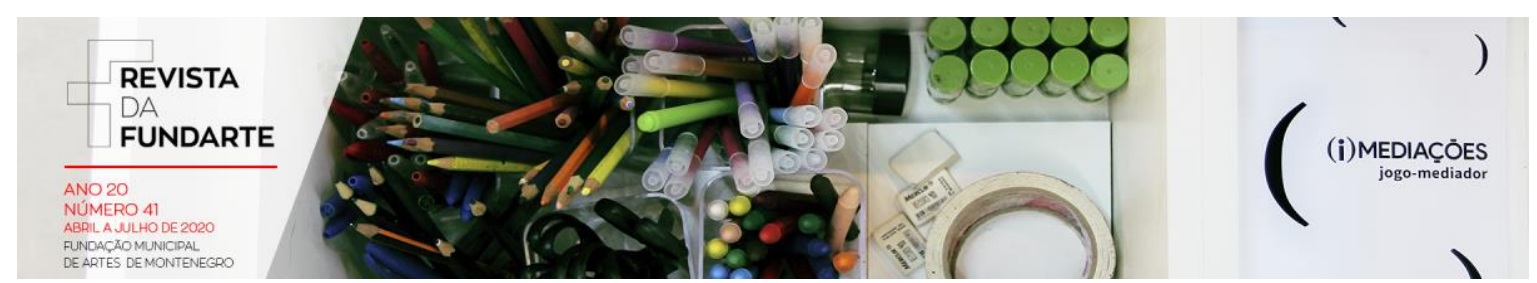

\title{
EDUCAÇÃO MUSICAL NO CONTEXTO DE JOVENS E ADULTOS COM DIVERSIDADE FUNCIONAL INTELECTUAL: RECURSOS DE APRECIAÇÃO MUSICAL
}

\author{
Edson Ribeiro Biondo Júnior ${ }^{1}$ \\ Diewerson do Nascimento Raymundo²
}

Resumo: Este artigo compartilha uma pesquisa, ainda em andamento, que tem buscado compreender como a apreciação musical pode compor a prática pedagógica de docentes que trabalham com jovens e adultos com diversidade funcional intelectual. A pesquisa-ação, como metodologia de pesquisa oferece apoio às investigações em grupo, registradas por diário de campo e vídeos das aulas ministradas em uma escola especial. A fundamentação teórica se dá pelo diálogo entre educação musical e educação especial; do conceito de diversidade funcional e práticas de apreciação musical. Os resultados parciais demostram benefícios ao fazer e à aprendizagem musical dos alunos que tiveram contato com musicogramas e musicovigramas nas aulas de música.

Palavras-chave: Educação Musical Especial; Apreciação Musical Ativa; Diversidade Funcional Intelectual.

\section{MUSICAL EDUCATION IN THE CONTEXT OF YOUTH AND ADULTS WITH INTELLECTUAL FUNCTIONAL DIVERSITY: RESSOURCES OF MUSICAL APPRECIATION}

\begin{abstract}
This article shares a research, still in progress, that has sought to understand how musical appreciation can compose the pedagogical practice of teachers who work with young people and adults with intellectual functional diversity. Action research, as a research methodology, offers support to group investigations, recorded by field diaries and videos of classes taught at a special school. The theoretical foundation is given by the dialogue between music education and special education; from the concept of functional diversity and practices of musical appreciation. The partial results show benefits to the making and music learning of students who had contact with musicograms and musicovigrams in music classes.
\end{abstract}

Keywords: Special Musical Education; Active Musical Appreciation; Intellectual Functional Diversity.

\section{Apontamentos Prévios}

A presente pesquisa surgiu a partir do trabalho com alunos da Educação de Jovens e Adultos (EJA), e a importância dada por eles durante as atividades de apreciação musical nas aulas de música da escola. Tais ações despertaram maior

\footnotetext{
${ }^{1}$ Professor de Música da Prefeitura Municipal de Porto Alegre; Licenciado em música (IPA); Especializa em educação musical (UERGS); Mestrando da pós-graduação em educação da UERGS. 2 Ator e arte/educador, realiza assessoria educativa em arte nos espaços educativos do Sesc/RS. Mestrando em Educação do Programa de Pós-Graduação da UERGS. Desenvolve pesquisas sobre artes especialmente práticas corporais destinadas às crianças pequenas
}

BIONDO JÚNIOR, Edson Ribeiro; RAYMUNDO, Diewerson do Nascimento. Educação Musical no contexto de jovens e adultos com diversidade funcional intelectual: recursos de Apreciação Musical. Revista da FUNDARTE. Montenegro, p.01-21, ano 20, № 41, Abril/Junho de 2019.

Disponível em: http://.seer.fundarte.rs.gov.br/index.php/RevistadaFundarte/index> 30 de junho de 2020. 


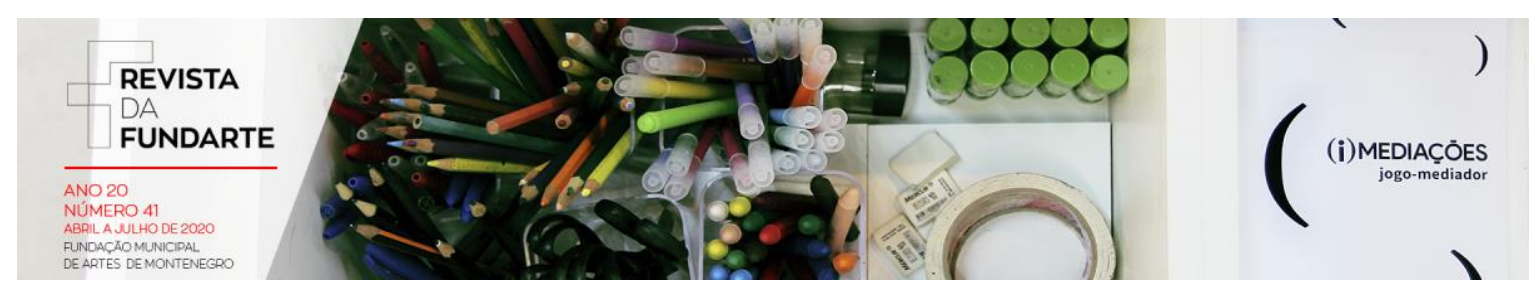

envolvimento do grupo e contribuíram para qualificação dos movimentos corporais dos alunos a partir da experiência de escuta dos sons.

Ao buscar meios para promover a educação musical para uma escola especial para jovens e adultos, a apreciação musical surgiu como uma força impulsionadora do fazer musical. Logo, foi comum que vários alunos se levantassem para dançar, outros preferiram cantar, mas de alguma forma todos se motivaram e foram mobilizados pela vivência com a música, inclusive alunos com a oralidade comprometida ou necessitados da cadeira de rodas para locomoção.

A apreciação musical, no presente trabalho é compreendida pelas formas dirigidas de se escutar música, atenta e criticamente, aliada a sua organização e sequenciação com o objetivo de se fazer música, auxiliando na externalização de movimentos corporais, no aceso de memórias afetivas e suscitando participação de todos, para que contribuam de diferentes modos.

O que estava em evidência não eram as limitações individuais que cada um apresentava, mas sim a potencialidade trazida pelos gestos, pelos cantarolares e até mesmo pelos olhares de cada um durante os momentos da aula de música. Um conceito importante que fundamenta esta pesquisa é não pensar na ótica do déficit, da falta que a palavra deficiência carrega na sua bagagem de significados, mas na diversidade de modos de ser e de existir que o termo diversidade funcional ${ }^{3}$ possui, não negando a diferença, ao mesmo tempo em que almeja a transformação de representações sociais desfavoráveis.

$\mathrm{Na}$ escola pesquisada, é comum os alunos pedirem por suas músicas prediletas, dançarem e cantarem. Devido à diversidade de idades do grupo, há muitos que preferem músicas de décadas anteriores, como por exemplo, canções sertanejas da década de noventa. Como professor de música, coube acolher essas vivências musicais dos alunos e propor atividades importantes para 0 aprimoramento musical, tais como: percussão corporal, execução instrumental, exercícios para a pulsação, técnica vocal, etc.

\footnotetext{
${ }^{3}$ No subtítulo ‘Conceitos e Referências' o termo é esclarecido.
}

BIONDO JÚNIOR, Edson Ribeiro; RAYMUNDO, Diewerson do Nascimento. Educação Musical no contexto de jovens e adultos com diversidade funcional intelectual: recursos de Apreciação Musical. Revista da FUNDARTE. Montenegro, p.01-21, ano 20, oㅡ 41, Abril/Junho de 2019.

Disponível em: http://.seer.fundarte.rs.gov.br/index.php/RevistadaFundarte/index> 30 de junho de 2020. 




Foi nesse contexto, de aprimorar as aprendizagens musicais dos alunos e aproveitar a potência que a apreciação musical demonstrou nesse processo, que surgiram os questionamentos que orientaram esta pesquisa e motivaram a problematização de como a apreciação musical poderia compor a prática pedagógica do docente que trabalha com jovens e adultos com diversidade funcional intelectual. Pensar em apreciação musical ativa é pensar em como utilizar os sons, a música, o movimento, imagens e os gestos para se fazer música.

Buscando oferecer um panorama mais detalhado da pesquisa, o texto será dividido em cinco partes: a) apresentação dos conceitos e referências que orientaram o estudo; b) apresentação da escola que se realizou a pesquisa; c) os procedimentos metodológicos; d) análise e discussão preliminar dos dados; e) considerações finais.

\section{Conceitos e Referências}

A educação musical no contexto da educação especial possui algumas especificidades que são necessárias ao professor para iniciar um trabalho pedagógico.

Um entendimento inicial é a necessidade de entender que a visão que a sociedade possui do que hoje comumente é chamado de pessoa com deficiência tem se alterado ao longo dos anos, assim como sua nomenclatura e formas de educação consideradas adequadas para suprir as demandas desse público.

Viviane Louro (2012; 2013a) nos diz que atualmente vivemos no paradigma do suporte, que alega que a sociedade precisa oferecer suporte para que as pessoas com deficiência participem de todos os âmbitos da sociedade, com maior autonomia possível. Ela explica que antes de chegarmos a esse ponto, tivemos dois outros paradigmas: o paradigma de institucionalização, que pregava que as pessoas com deficiências deveriam ficar isoladas em instituições específicas, fora do convívio social, e o paradigma de serviço, que pregava que a pessoa com deficiência poderia ser integrada na sociedade depois de passar por um processo de normalização. A

BIONDO JÚNIOR, Edson Ribeiro; RAYMUNDO, Diewerson do Nascimento. Educação Musical no contexto de jovens e adultos com diversidade funcional intelectual: recursos de Apreciação Musical. Revista da FUNDARTE. Montenegro, p.01-21, ano 20, oㅡ 41, Abril/Junho de 2019.

Disponível em: http://.seer.fundarte.rs.gov.br/index.php/RevistadaFundarte/index> 30 de junho de 2020. 


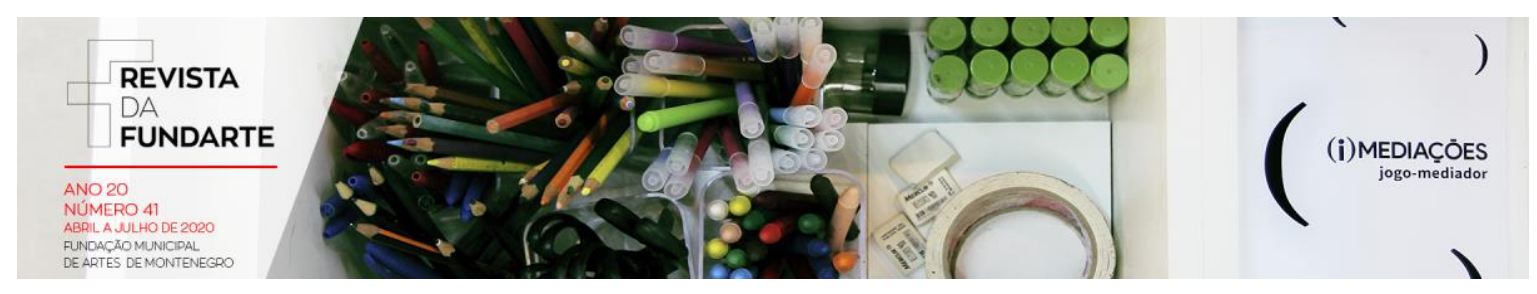

sociedade prestaria o serviço de treiná-la em instituições especializadas e, quando estivesse apta, seria caminhada ou reencaminhada para a vida na comunidade.

Para a autora, o paradigma de suporte prega o respeito à individualidade das pessoas e uma sociedade que ofereça as mesmas oportunidades para todos os indivíduos, independentemente de suas questões físicas, cognitivas ou comportamentais. No paradigma do suporte cabe à sociedade adequar-se às necessidades das pessoas, cabe a escola promover adaptações para incluir o aluno com deficiência e cabe ao professor ter conhecimento sobre as questões pedagógicas e estruturais que envolvam atividades relacionadas às pessoas com deficiência.

Para que essa mudança de paradigma se efetive de maneira adequada é necessário ir além de mudanças arquitetônicas nas instituições e leis que obriguem a matrícula na escola regular/comum. É necessário oferecer programas internos de acessibilidade, maneiras alternativas para que pessoas com diversidade funcional usufruam dos diferentes espaços. Também é importante aprimorar a formação inicial dos professores com cursos complementares e ampliar os trabalhos acadêmicos nessa área, que apontem desafios, assim como possibilidades ou entendimentos sobre a prática docente.

Para que a música não seja uma arte para poucos, é fundamental respeitar as possibilidades de cada um e adaptar o fazer músico-pedagógico para aqueles que possuem algum tipo de diversidade funcional. Isso só pode ser alcançado com o fornecimento de informações suficientes que façam com que os tabus sejam dissolvidos e os estereótipos derrubados (LOURO, 2012).

Pensando em fortalecer essa mudança de paradigma para uma sociedade que realmente se importe e inclua, consciente que a linguagem orienta, produz e modifica o pensamento da sociedade, esse trabalho propõe que ao invés do termo 'deficiência' se utilize 'diversidade funcional', termo mais próximo da neutralidade, que reconhece pessoas que operam diferentemente ao "padrão de normalidade" convencionado socialmente, mas não de forma pejorativa, não propondo pela ótica contexto de jovens e adultos com diversidade funcional intelectual: recursos de Apreciação Musical. Revista da FUNDARTE. Montenegro, p.01-21, ano 20, oㅡ 41, Abril/Junho de 2019.

Disponível em: http://.seer.fundarte.rs.gov.br/index.php/RevistadaFundarte/index> 30 de junho de 2020. 


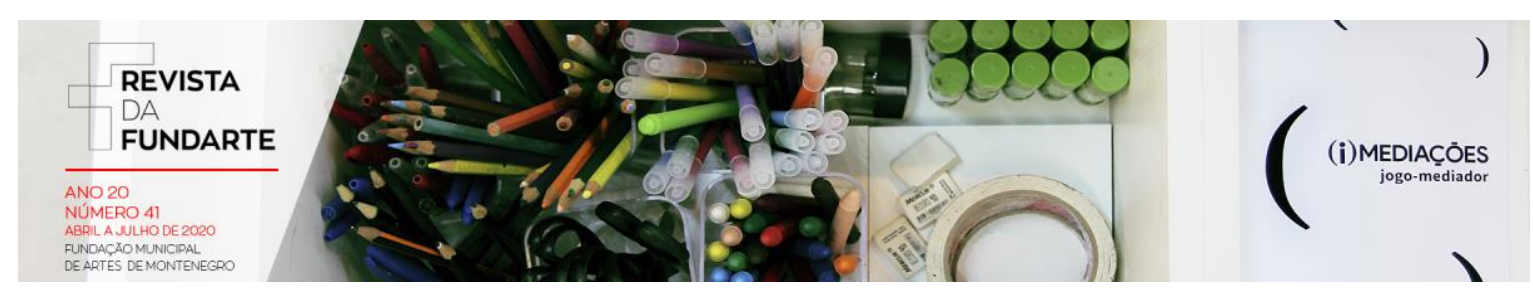

do déficit, da falta, da ineficiência ou da incapacidade, que muitas vezes a palavra deficiência pode nos levar.

O termo diversidade funcional surgiu de uma comunidade virtual, um fórum de discussão que nasceu em 2001 na Espanha, que debatia sobre direitos humanos de homens e mulheres com deficiência. Os integrantes buscaram um termo que não provocasse a desigualdade, e se afastasse da perspectiva de tratamentos excludentes. Em 2005, integrantes do grupo reivindicaram a mudança da terminologia discapacidad (deficiência) para diversidad funcional (diversidade funcional), inclusive criaram a sigla PDF (pessoa com diversidade funcional) extraída das letras iniciais das palavras (ROMAÑACH e LOBATO, 2005).

É importante entender que as palavras levam associadas ideias e conceitos, representando valores culturalmente aceitos do que está sendo nomeado, não são inocentes e refletem uma determinada concepção de realidade, de tal forma que mudando palavras e suas estruturas, em conjunto com a transformação das práticas pedagógicas, ajudamos a mudar a visão e as formas de existir sobre a realidade social.

[...] cada cultura e cada época apresentam concepções próprias de diversidade funcional, englobando crenças ou mitos explicativos, bem como formas de tratamento da questão, o que resulta num leque de procedimentos e atitudes que variam entre segregação social, eliminação sumária, divinização, acolhimento ou indiferença. Independentemente da concepção de diferença funcional, dos rituais ou das formas de tratamento, ou mesmo do status social dessas pessoas em uma sociedade, a diferença funcional e tudo aquilo que a ela se vincula constituem partes integrantes daquela sociedade e daquela cultura, mesmo que nela a segregação ou a eliminação sejam práticas comuns. Surgem, assim, concebidos e reforçados pela cultura, os modelos tomados como referência para a aparência, a forma e o funcionamento do corpo. (PEREIRA, 2009, p. 717).

Para um melhor entendimento dos termos propostos, buscamos apoio no dicionário para esclarecer o significado das palavras diversidade funcional:

“Diversidade: Variedade; diferença” (BUENO, 2001, p.264).

"Funcional: Decorrente de uma função; do exercício ou trabalho de algum órgão; adequado ou apropriado a uma função, a uma utilidade; prático" (BUENO, 2001, p.374).

BIONDO JÚNIOR, Edson Ribeiro; RAYMUNDO, Diewerson do Nascimento. Educação Musical no contexto de jovens e adultos com diversidade funcional intelectual: recursos de Apreciação Musical. Revista da FUNDARTE. Montenegro, p.01-21, ano 20, oㅡ 41, Abril/Junho de 2019.

Disponível em: http://.seer.fundarte.rs.gov.br/index.php/RevistadaFundarte/index> 30 de junho de 2020. 


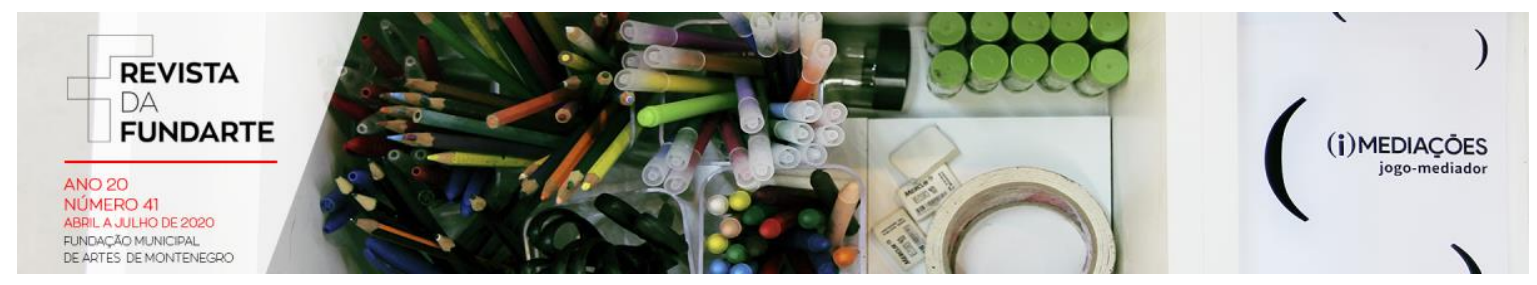

Palacios e Romañach (2006) criticam o modelo social que coloca a pessoa com diversidade funcional como uma pessoa incapaz. A ênfase para esses autores deve ser a dignidade da vida humana. Todas as pessoas podem apresentar alguma 'deficiência' ao longo de sua vida, fato que demonstra a importância de legislar levando em conta esse princípio. Dessa maneira a diversidade funcional é uma constante na vida de todos os seres humanos, que todos somos, em algum momento da vida, pessoas com funcionalidade diversas. O termo dessa forma, tem uma característica neutra, livre de conotações negativas, não valorativo, não designando somente um coletivo normalmente marginalizado, mas toda espécie, que em maior ou menor grau, foi, é ou será, uma pessoa com diversidade funcional.

Esse enfoque que promove a adoção do termo 'diversidade funcional' como substituto à 'deficiência', é tendência em nível internacional como uma corrente de linguagem e pensamento que contribui para a transformação de representações sociais desfavoráveis. Essa concepção se pergunta se realmente uma pessoa 'sem deficiência' pode fazer absolutamente todas as coisas e desempenhar qualquer tarefa sem dificuldade ou auxilio. Buscando a reflexão que, assim como ocorre com qualquer pessoa, existe um conjunto de coisas que se se faz com facilidade, outras não, um conjunto de capacidades físicas ou mentais que são únicas para cada indivíduo (DÍAZ-POSADA e RODRÍGUEZ-BURGOS, 2016).

Apesar da busca por esse olhar mais acolhedor da diversidade funcional, não se almeja esquecer ou abrandar a realidade. Visto que é reconhecido que pessoas com diversidade funcional são diferentes do ponto de vista médico da maior parte da população (ROMAÑACH e LOBATO, 2005). Sobre os grupos específicos, os autores sugerem que seja utilizado os termos específicos, como diversidade funcional intelectual ao invés de deficiência intelectual, assim como demais grupos podem também ser nomeados: diversidade funcional física, diversidade funcional auditiva, diversidade funcional visual, diversidade funcional orgânica, etc. O grupo que foi realizada a pesquisa-ação é formado por pessoas com diversidade funcional intelectual.

BIONDO JÚNIOR, Edson Ribeiro; RAYMUNDO, Diewerson do Nascimento. Educação Musical no contexto de jovens e adultos com diversidade funcional intelectual: recursos de Apreciação Musical. Revista da FUNDARTE. Montenegro, p.01-21, ano 20, oㅜ 41, Abril/Junho de 2019.

Disponível em: http://.seer.fundarte.rs.gov.br/index.php/RevistadaFundarte/index> 30 de junho de 2020. 


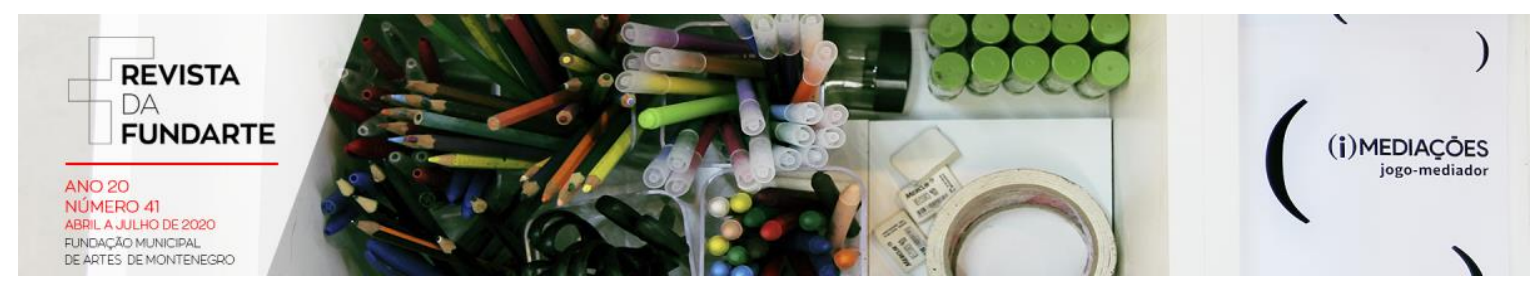

Para a construção das aulas que fizeram parte da realização da pesquisa foi usado como referencial teórico sobre apreciação musical o conceito de Jos Wuytack, juntamente com um recurso visual para apreciação musical (musicograma) criado por ele, um notável músico belga nascido em 1935, aluno e amigo de Carl Orff. Um dos principais focos de trabalho de Wuytack é a audição, não de modo passivo, mas sim com uma postura ativa por parte do aluno.

As atividades de audição musical ativa devem oferecer meios para que os alunos escutem a música de modo atento, visando o desenvolvimento de autonomia crítica e a capacidade de escutar com a possibilidade de transitar entre os vários âmbitos possíveis de organização e estruturação musical (GREBORE, 2013, p.1).

A apreciação musical é também uma forma de fazer musical, onde o aluno não é somente um ser passivo, mas envolvido em um processo de escuta prioritariamente ativo. A apreciação ativa significa uma escuta intencional e focada, na qual o ouvinte está concentrado de forma física e intelectual, enquanto que a audição passiva supõe um nível baixo de atenção, como ocorre, por exemplo, quando se escuta música de fundo ou como mero acompanhamento de outras atividades não musicais (WUYTACK; PALHEIROS, 2009, tradução nossa).

Uma das principais contribuições de Wuytack, pouco abordadas por Orff, foi a audição musical ativa, sobretudo a indivíduos que não conhecem a notação musical tradicional. A audição musical ativa de Wuytack é apoiada pela percepção visual. Essa audição envolve a expressão verbal, corporal ou instrumental na visualização de um esquema de música, um recurso visual, que Wuytack chamou de musicograma.

O musicograma "(...) é um registro gráfico em que os elementos essenciais da obra ou excerto musical (forma, ritmo, melodia, timbre, instrumentação, orquestração) são representados através de cores, formas geométricas e símbolos" (PALHEIROS e BOURSCHEIDT, 2012, p.324).

Wuytack orienta que na utilização do musicograma, a música seja escutada três vezes. A primeira com uma impressão geral sobre a música, uma segunda escuta seguindo a orientação do professor no musicograma, que deve indicar a

BIONDO JÚNIOR, Edson Ribeiro; RAYMUNDO, Diewerson do Nascimento. Educação Musical no contexto de jovens e adultos com diversidade funcional intelectual: recursos de Apreciação Musical. Revista da FUNDARTE. Montenegro, p.01-21, ano 20, oㅡ 41, Abril/Junho de 2019.

Disponível em: http://.seer.fundarte.rs.gov.br/index.php/RevistadaFundarte/index> 30 de junho de 2020. 


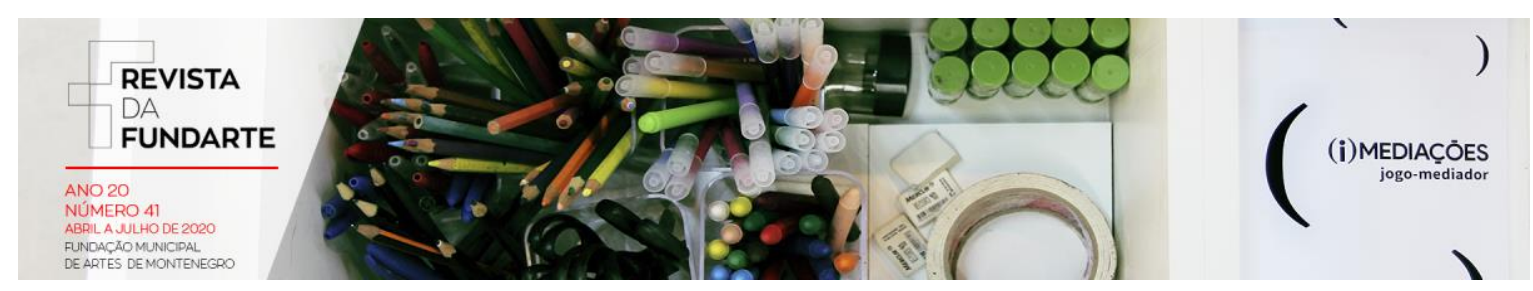

pulsação e onde se encontra a figura ou símbolo, e uma terceira audição com os alunos indicando em seus musicogramas os temas da música. Essa indicação busca ajudar na autonomia do aluno durante a audição, mostrando sua compreensão da música. O professor pode observar as dificuldades dos alunos, ajudando a compreender os elementos (WUYTACK e PALHEIROS, 2009, tradução nossa).

Abaixo segue um musicograma, que exemplifica a proposição de Jos Wuytack, com variadas figuras, intensidades, cores e indicação de duração.

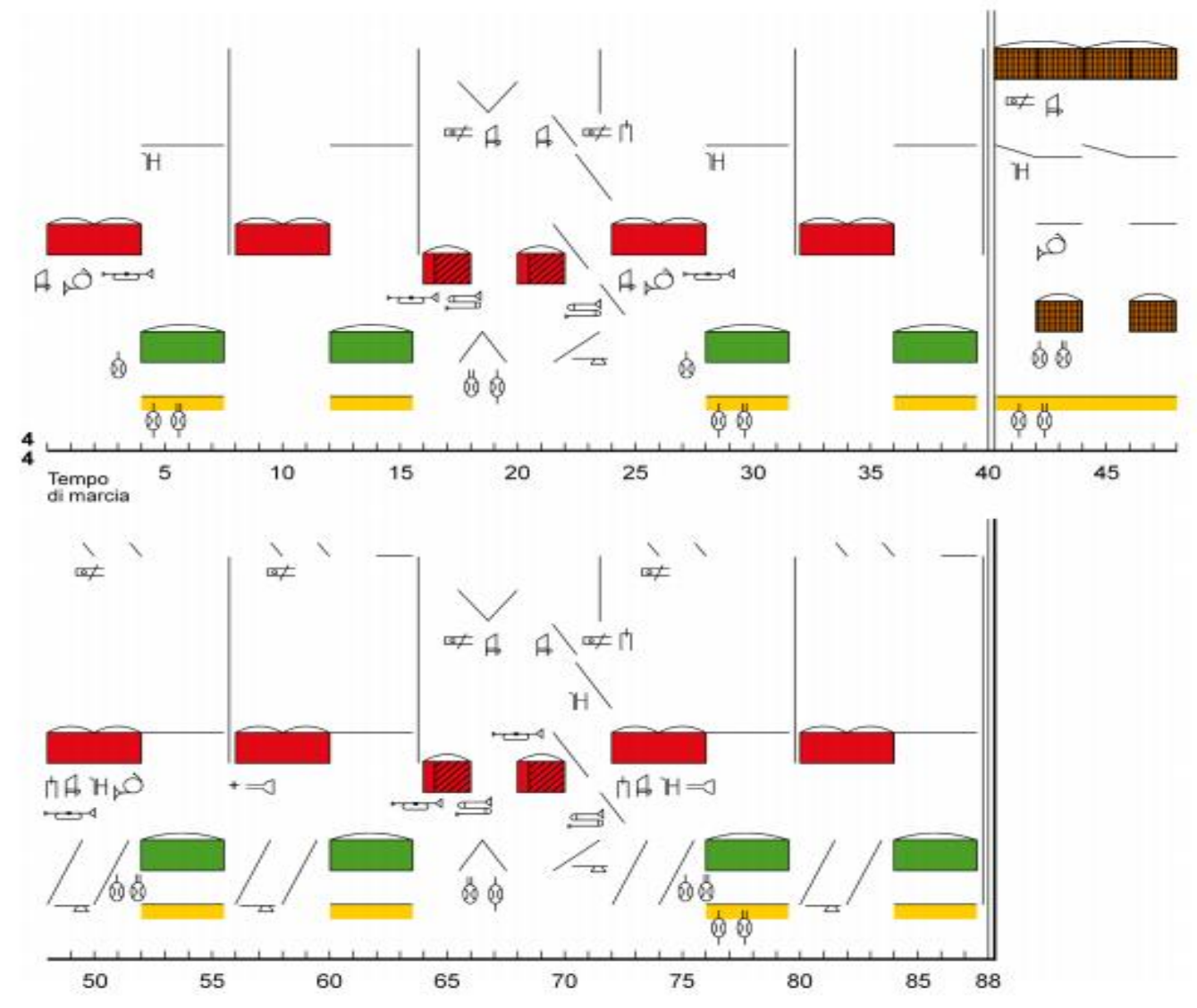

Figura 1 - Musicograma - Tchaikovsky - Suíte Cascanueces. Fonte: WUYTACK e PALHEIROS, 2009 p.53.

É importante ressaltar que os musicogramas foram criados no início da década de 70, na Europa, para se aprender música erudita. Para a presente pesquisa, em nosso contexto, foram realizadas algumas modificações para proporcionar a aprendizagem com o público-alvo, pessoas com diversidade funcional intelectual. Em vez de símbolos, cores ou formas geométricas propostas

BIONDO JÚNIOR, Edson Ribeiro; RAYMUNDO, Diewerson do Nascimento. Educação Musical no contexto de jovens e adultos com diversidade funcional intelectual: recursos de Apreciação Musical. Revista da FUNDARTE. Montenegro, p.01-21, ano 20, oㅡ 41, Abril/Junho de 2019.

Disponível em: http://.seer.fundarte.rs.gov.br/index.php/RevistadaFundarte/index> 30 de junho de 2020. 




por Jos Wuytack, foram utilizadas imagens de partes do corpo (pés, mãos, coxas, etc.) para auxiliar o trabalho de percussão corporal. Também se utilizou de imagens de instrumentos (clavas, triângulo, etc.) para a execução instrumental.
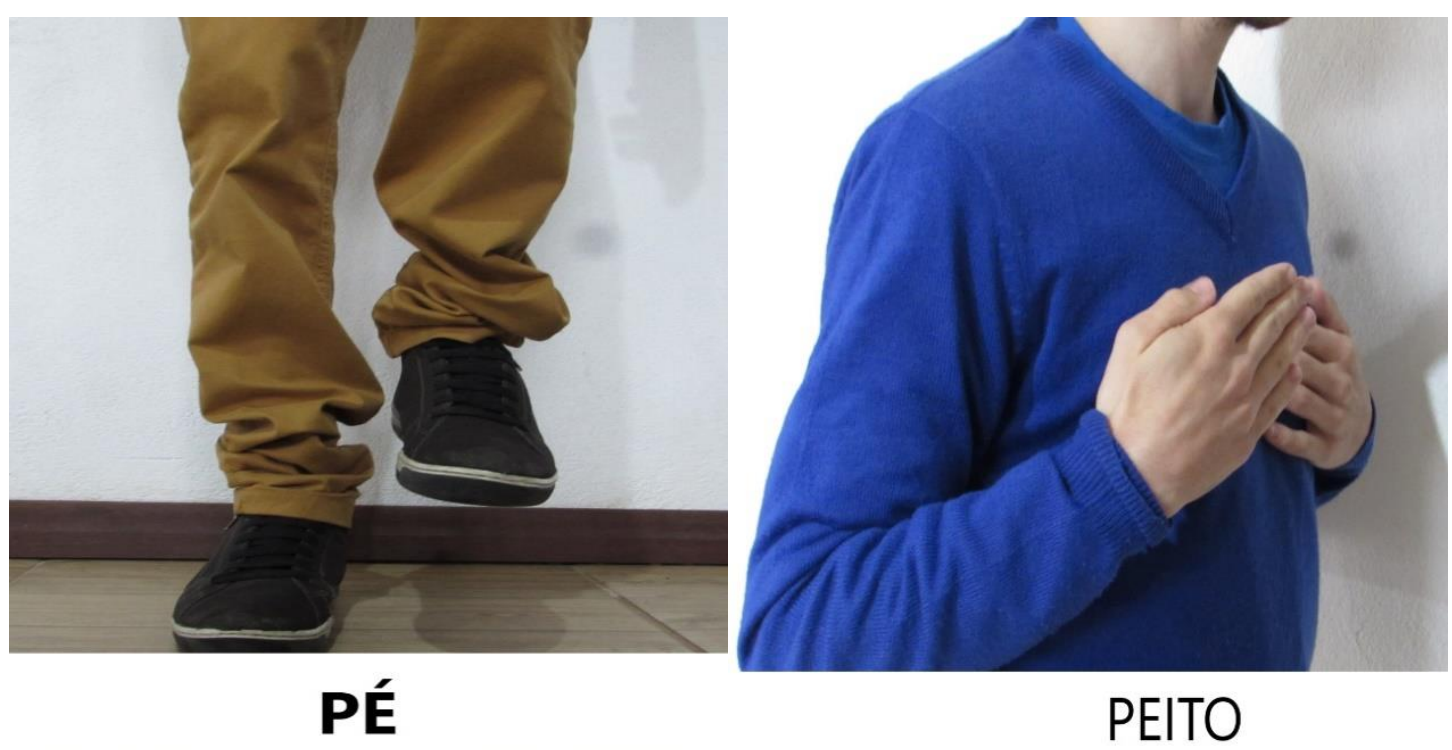

Figura 2 - Fotografias utilizadas para compor a sequência rítmica dos musicogramas. Fonte: acervo autor.

Algo importante para as aulas na Educação de Jovens e Adultos (EJA) é respeitar essa fase da vida e não infantilizar os alunos. Por isso, foram utilizadas fotografias de corpos adultos (professor e dos alunos) para confecção dos musicogramas.

Os musicogramas foram utilizados como cartas que podiam ser mudadas de ordem pelos alunos e pelo professor, tendo como objetivos que os alunos incialmente identificassem a sonoridade que escutaram com a sua relativa percussão corporal e num segundo momento consigam visualizar e executar a sequência de sons utilizados na música.

Recursos concretos que associam sons a imagens, palavras, cores nas exemplificações, bem como processos de criação, facilitam o armazenamento e o acesso ao conhecimento, pois ao mesmo tempo trabalham diferentes regiões do cérebro, tornando possível o funcionamento concomitante de partes importantes. 2020. 


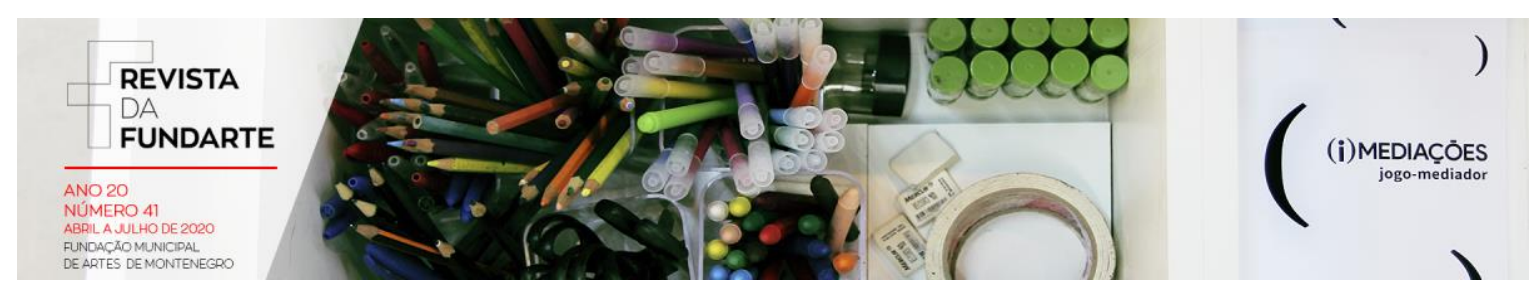

Diante da diversidade funcional intelectual é fundamental ser claro e objetivo com o que é proposto, utilizando frases simples e exemplos do cotidiano. Esses elementos auxiliam na compreensão por parte do aluno, que costuma trazer dificuldade quanto à abstração, a generalização e a aquisição de conceitos. Assim, quanto mais variados e concretos os recursos, mais facilidade o aluno terá para a aprendizagem (LOURO, 2012). A educadora musical, enfatiza ainda que a consolidação de qualquer aprendizagem só é possível através da abstração. Sem ela não é possível chegar ao conceito de algo. Através da abstração podemos imaginar os resultados de uma decisão ou de uma ação sem recorrermos a mecanismos físicos. A abstração está diretamente relacionada à generalização, que é a capacidade de classificar as coisas por suas características, organizando-as em grupos separados. Com a capacidade de abstração e da generalização podemos conhecer suas qualidades e elaborar conceitos. Esses três elementos (abstração, generalização e conceito) são para muitas pessoas com diversidade funcional intelectual, difíceis de serem compreendidos.

Uma tecnologia que pode auxiliar a apreciação musical ativa é a possibilidade de utilização de vídeos nesse processo. O musicovigrama é um tipo de musicograma, mas em formato de vídeo. Existem algumas grafias alternativas baseadas nos musicogramas de Wuytack: algumas em formato de vídeos sem conter movimento, outras contêm animação ou movimento indicando acontecimentos posteriores, algumas misturam símbolos, imagens e notação musical tradicional. Esse último exemplo se afasta do sentido original de musicograma proposto por Jos Wuytack (OLIVEIRA, J., OLIVEIRA, 2019), devido a busca do autor por formas alternativas de propor a interpretação e leitura dos sons. contexto de jovens e adultos com diversidade funcional intelectual: recursos de Apreciação Musical. Revista da FUNDARTE. Montenegro, p.01-21, ano 20, oㅡ 41, Abril/Junho de 2019.

Disponível em: http://.seer.fundarte.rs.gov.br/index.php/RevistadaFundarte/index> 30 de junho de 2020. 




A pedagogia musical do autor é inspirada num pensamento milenar chinês, atribuído a um dos discípulos de Confúcio: "Diz-me, eu esqueço; mostra-me, eu recordo, envolva-me eu compreendo" (PALHEIROS e BOURSCHEIDT, 2012, p.315). Partindo dessa maneira de se pensar educação musical, com o envolvimento do aluno de forma central no processo educativo, as aulas buscaram levar elementos para tornar a apreciação musical uma capacidade que envolva o jovem e adulto e dê ferramentas para que ele possa se desenvolver musicalmente.



Figura 3 - Musicovigrama Vals №2 Shostakovich4.

Acima temos um exemplo de musicovigrama, vídeo utilizado durante as aulas, a valsa $\mathrm{n}^{\circ} 2$ de Shostakovich, cada vez que aparece o quadrado azul o aluno deve tocar o instrumento que está aparecendo no vídeo, no caso da imagem acima, a pandeireta, é tocada uma vez a cada pulsação da música, que é seguida no vídeo por prato, triângulo e clavas.

https://www.youtube.com/watch?v=ksJuwNhlO7g

BIONDO JÚNIOR, Edson Ribeiro; RAYMUNDO, Diewerson do Nascimento. Educação Musical no contexto de jovens e adultos com diversidade funcional intelectual: recursos de Apreciação Musical. Revista da FUNDARTE. Montenegro, p.01-21, ano 20, oㅡ 41, Abril/Junho de 2019.

Disponível em: http://.seer.fundarte.rs.gov.br/index.php/RevistadaFundarte/index> 30 de junho de 2020. 


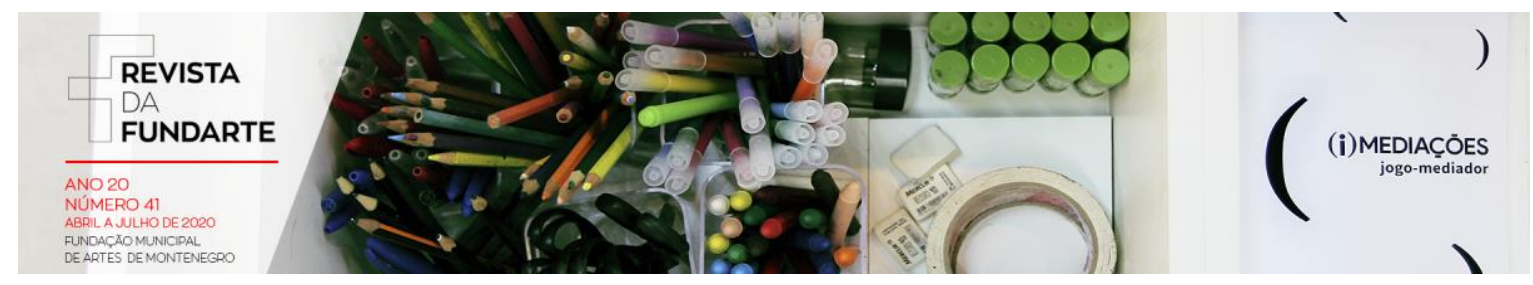

\section{A Escola}

A escola CrêSer tem como um dos seus principais diferenciais atender alunos com diversidade funcional intelectual maiores de 21 anos. Nas escolas da Rede Municipal de Porto Alegre, os alunos só podem fazer parte até os 20 anos; ao completar 21, devem se formar e sair da escola. Muitos jovens e famílias ficam desorientadas, pois gostariam que seus filhos continuassem a frequentar uma escola. Dessa necessidade surgiu a Crêser, atendendo os alunos que vieram da Rede Municipal ou que não haviam conseguido estudar quando crianças. Com a intenção de unir educação permanente (ao longo de toda a vida) e a possibilidade de pessoas com diversidade funcional intelectual comporem alguma fonte de renda, surgiu a Cooperativa Social Especial Crêser, organização não governamental, espaço para jovens e adultos com diversidade funcional intelectual ou outras diversidades funcionais associadas a intelectual, sendo inaugurada em 2000. Em 2001, a cooperativa começou a contar com o apoio da prefeitura fornecendo suporte técnico com profissionais capacitados.

O fato de a escola ter sua razão social como cooperativa traz seus benefícios e prejuízos, que de tempos em tempos são pesados e discutidos pelo grupo. Se por um lado a cooperativa facilita que todos os participantes sejam associados, o que pode gerar alguma renda a seus membros através dos produtos feitos nas oficinas no contraturno das aulas da escola; padaria, horta e papel reciclável, por outro, dificulta concretizar alguns convênios com empresas ou associações, assim como não se pode fazer doação de parte do imposto de renda para a escola. No ano de 2019, os dirigentes da organização (mães e pais dos alunos) realizaram os trâmites burocráticos para transformar a cooperativa em Instituto Social CrêSer.

Para o funcionamento da escola, a prefeitura oferece 5 profissionais: um professor de artes visuais, um professor de música, uma professora de educação física e dois professores com formação em educação especial. A prefeitura atualmente também oferece o lanche e o almoço para os alunos. Os responsáveis pelos alunos, normalmente as mães, dirigem as questões burocráticas, limpeza e 


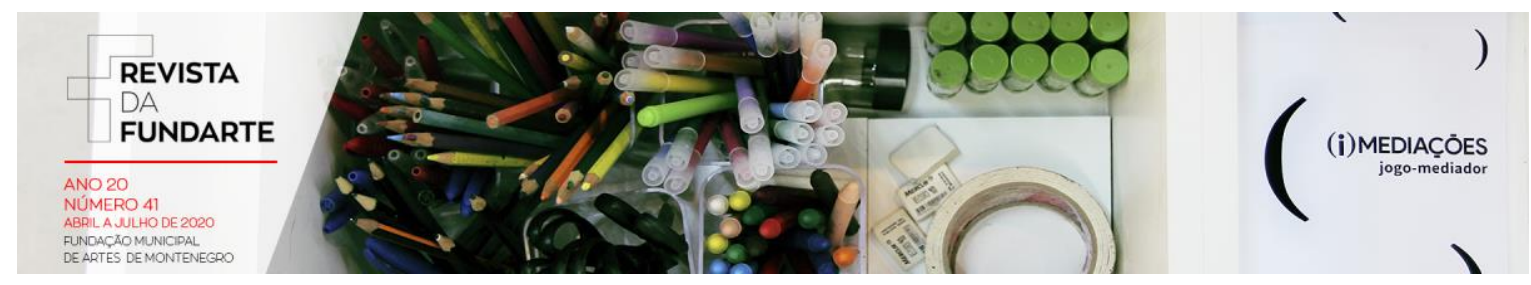

organização da escola. Os professores são responsáveis pela parte pedagógicoeducacional.

Ao todo são atendidos cerca de 30 alunos, matriculados na EJA. Os professores têm liberdade para, de acordo com o planejamento, dar aula individual para pequenos grupos, ou então trabalhar em dupla com algum colega para atender o grande grupo. Desde o início das aulas do atual professor de música na escola, em 2018, foi decidido trabalhar em conjunto com a professora de educação física com o grande grupo, foi percebido que o trabalho com o corpo feito na educação física e o trabalho com o corpo feito em música podem se aproximar e beneficiar o aprendizado dos alunos, desta forma, as atividades são planejadas cotidianamente em duplas.

A escola possui salas amplas que são muito utilizadas para os movimentos da educação musical e educação física. Possui alguns pandeiros, $\operatorname{tantan}^{5}$, violão, bateria, piano eletrônico, caixa de som e microfone, que são usados com frequência nos encontros semanais. Em anos anteriores os alunos já tiveram aula de música, ficando desde a aposentadoria da professora anterior, até o ano de 2018, sem professor da matéria. Todos foram receptivos a reinserção das aulas de música na escola. Percebe-se uma grande dedicação por parte dos alunos para realizar da melhor maneira possível as atividades. Os alunos costumam escutar com atenção os professores, embora nem sempre suas colocações tenham relação com o que está sendo conversado em sala, oferecendo um desafio ao professor de produzir formas de conectar sua disciplina com aquilo que produz desejos no aluno.

\section{Procedimentos metodológicos}

Existem muitos nomes para inúmeros tipos de pesquisa-ação. Para Trip (2015), investigação-ação é um termo genérico para qualquer processo que siga um ciclo no qual se aprimora a prática pela oscilação sistemática entre agir no campo da

\footnotetext{
${ }^{5} \mathrm{O}$ Tantan também é conhecido como tantã ou rebolo. É um instrumento de percussão, que consiste de um tipo de tambor de formato cilíndrico ou afunilado, muito utilizado no samba.
} contexto de jovens e adultos com diversidade funcional intelectual: recursos de Apreciação Musical. Revista da FUNDARTE. Montenegro, p.01-21, ano 20, № 41, Abril/Junho de 2019.

Disponível em: http://.seer.fundarte.rs.gov.br/index.php/RevistadaFundarte/index> 30 de junho de 2020. 


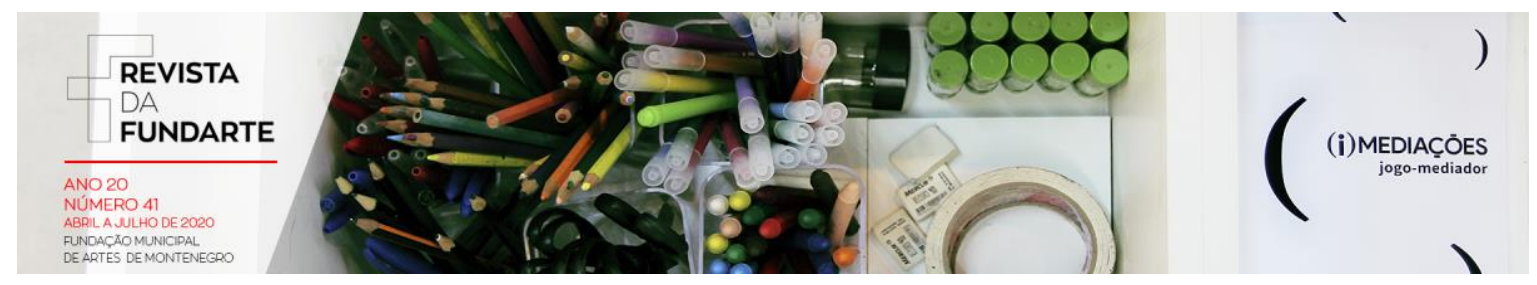

prática e investigar a respeito dela. Planeja-se, implementa-se, descreve-se e avaliase uma mudança para a melhora de sua prática, e no decorrer do processo vai se aprendendo mais, tanto a respeito da prática quanto da própria investigação.

\section{Diagrama 1: Representaçẫo em quatro fases do cicło básico da investigaçăo-açăo.}

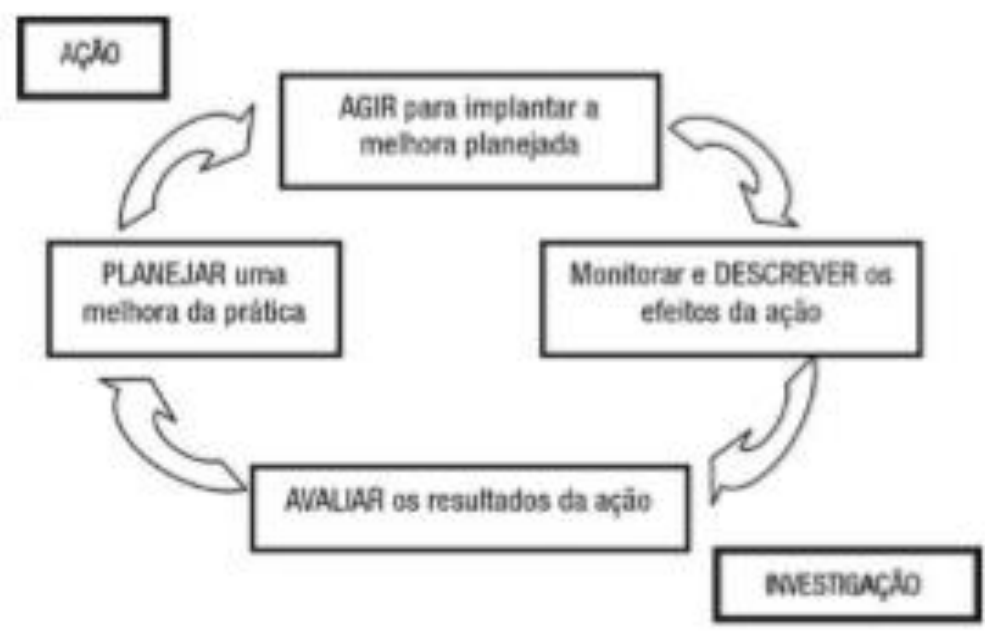

Figura 4 - Ciclo da Pesquisa-ação. Fonte: David Trip (2005, p.446).

Trip (ibdem) não coloca a reflexão como uma das quatro atividades (planejar, implementar, descrever e avaliar). Para o autor, a reflexão está presente em todas as etapas do ciclo, sendo uma das principais características da pesquisa-ação, a capacidade dos autores refletirem sobre seus problemas para poder re-planejar a prática. A observação também é um elemento presente durante toda a abordagem do ciclo.

A pesquisa-ação se deu através de oito encontros durante a aula de música realizados no segundo semestre de 2019. Para fins de formação do grupo de investigação da pesquisa, além do professor de música, participaram todos os alunos da escola CrêSer (próximo a trinta alunos) e a professora de educação física, que ficaram corresponsáveis pela reunião de avaliação e replanejamento das aulas de música. 


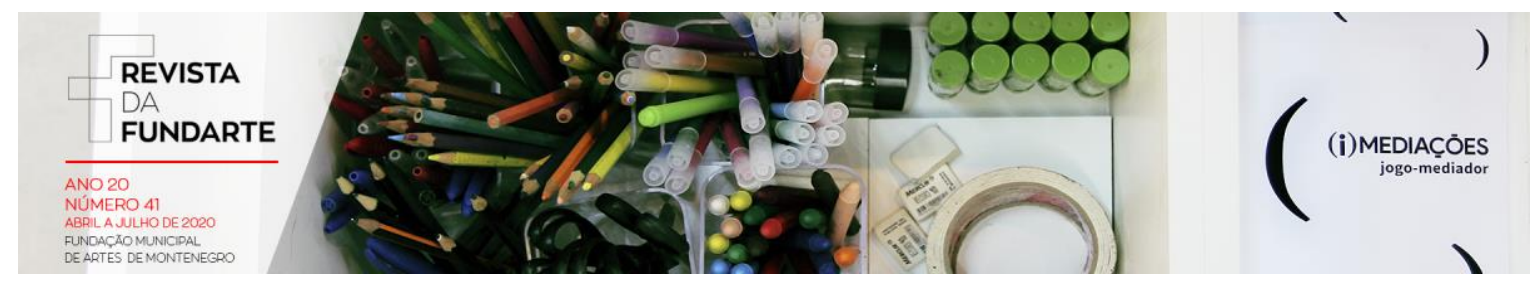

Os encontros tiveram em torno de uma hora de atividades musicais e cerca de trinta minutos de discussão com o grupo de investigação para avaliar as práticas e replanejar os próximos encontros.

O fato de se tratar de um grupo formado por alunos com diversidade funcional intelectual requer que esta pesquisa-ação tenha um cuidado particular em entender o que esses alunos estão buscando dizer. Muitas vezes essa resposta pode não vir de uma forma oral direta, sendo necessário interpretar os alunos como um todo e não apenas sua fala, levando em consideração também os seus corpos, feições e sentimentos.

Diferente de outras formas de pesquisa, na pesquisa-ação não se segue uma série de fases rigidamente ordenadas à priori, devido aos imprevistos que aparecem ao longo das práticas. São diferentes preocupações ao longo do processo devido às circunstâncias e a dinâmica interna do grupo de pesquisadores e da situação a ser investigada (Thiollent, 2011).

A coleta de dados para essa pesquisa foi realizada utilizando os seguintes instrumentos: diário de campo e gravações em áudio e/ou vídeo.

As práticas propostas, diálogos e reflexões foram registrados no diário de campo, buscaram dar voz aos professores e alunos que participam da pesquisa, registrando o mais próximo possível temporalmente suas inquietações, questionamentos, dúvidas e os sentimentos que a atividade proporcionou.

As gravações em áudio e vídeo auxiliaram na reflexão à posteriori, procurando por elementos que durante os encontros da aula de música/pesquisaação possam ter passado despercebidos ou que não foram dados o devido valor, possibilitando novas análises e entendimentos sobre as práticas.

Tratando-se do campo da educação e, mais especificamente, da educação musical especial, que se caracteriza como um campo de interface entre educação musical e educação especial (Morales e Bellochio, 2009), uma capacidade fundamental que o professor precisa aprender é a observar com estreita atenção. Nem sempre é fácil identificar onde se encontra a dificuldade de aprendizagem. A clareza virá com a observação atenta aos poucos, com o educador propondo-se a contexto de jovens e adultos com diversidade funcional intelectual: recursos de Apreciação Musical. Revista da FUNDARTE. Montenegro, p.01-21, ano 20, oㅡ 41, Abril/Junho de 2019.

Disponível em: http://.seer.fundarte.rs.gov.br/index.php/RevistadaFundarte/index> 30 de junho de 2020. 


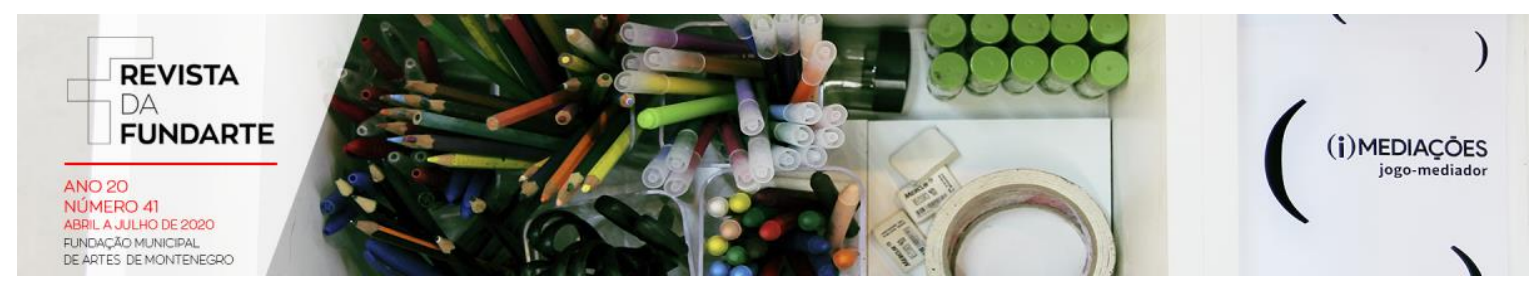

compreender a dificuldade do aluno e estabelecendo estratégias à luz dessas descobertas (LOURO, 2012).

A capacidade de "ler o aluno" é bastante desejável, pois o aluno com diversidade funcional intelectual muitas vezes tem comprometimento da sua oralidade. Muitas palavras podem parecer incoerentes e desconexas; ou ele pode sinalizar suas intenções com gestos e expressões faciais que não estamos acostumados. Dessa forma, a observação é importantíssima para o trabalho do professor. Na CrêSer essa capacidade também pode se dar com a ajuda dos demais colegas, visto que o trabalho coletivo e o diálogo entre os professores é um hábito na escola.

\section{Análise e Discussão Preliminar dos Dados}

Por se tratar de uma pesquisa em andamento, esta investigação se encontra na etapa de análise dos dados coletados. Alguns apontamentos podem ser elaborados baseados na coleta de dados dos oito encontros da pesquisa-ação. São eles:

a) Musicogramas são ferramentas importantes para utilização de recursos concretos na educação musical. Ao verem as partes do corpo utilizadas durante a percussão corporal em imagens na sua frente, os alunos tinham outra referência além do professor para memorizarem a sequência, ficando o professor mais livre para ir até os lugares dos alunos individualmente e ajudar quem eventualmente tinha dificuldades em realizar a sequência.

b) Os alunos ou professor podiam sugerir e mudar a sequência de musicogramas, esse processo foi realizado algumas vezes durante os encontros, tornando as músicas que foram ensaiadas mais acessíveis e com maior envolvimento dos alunos nesse processo de organização da percussão corporal. Além de possibilitar a criação de repertórios próprios que a cada encontro foi se estabelecendo, dentro das possibilidades do próprio grupo. 



Figura 5 - Estrutura suporte do musicograma que resguarda as fotografias organizadas de acordo com a intencionalidade. Fonte: acervo do autor.

c) Já os musicovigramas foram ferramentas que através de imagens em vídeos impulsionaram a prática coletiva com os instrumentos musicais, fortalecendo o domínio da pulsação da música, de tocar e parar de tocar de acordo com a estrutura da música, da capacidade de ouvir o colega tocando e se organizar para entrar no tempo certo.

d) Atividades de apreciação musical que propiciaram a escuta de músicas executadas em diferentes versões, estimularam a reflexão e o debate dos alunos sobre se era a mesma música que estava sendo escutada, quais os instrumentos que estavam presentes em cada uma, se era executada em duo ou grupo, etc. Essas referências foram auxiliares no momento da execução da música por parte dos alunos, visto que deram elementos musicais diversos para o aluno, tornando sua execução instrumental mais rica. 


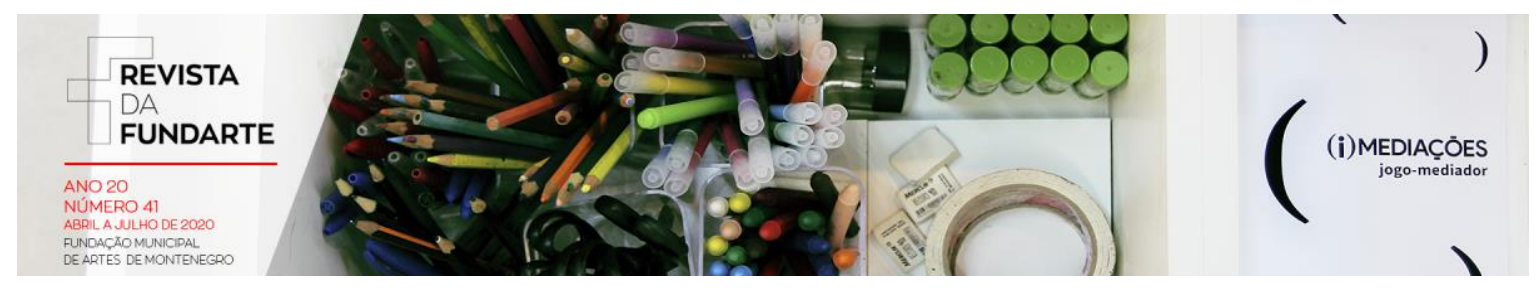

Importante destacar que ao ter o recurso visual, elemento importante para facilitar a aprendizagem (LOURO, 2012), os alunos puderam desenvolver a capacidade de sequenciação de elementos e a capacidade de associação e abstração, importantíssima para o trabalho com pessoas com diversidade funcional intelectual. Quando a organização neurológica interna é insuficiente, é preciso que ela seja estimulada externamente pelo professor, até que o aluno aprenda a organizar-se sem auxílio (LOURO, 2012).

A utilização dos musicogramas e musicovigramas possibilitaram desenvolver a capacidade de generalização, abstração e conceituação, o reconhecimento e associação das partes do corpo com o som que é emitido e a possibilidade da organização de sequência de sons por parte dos alunos.

Como no final de cada encontro sempre era feito uma conversa sobre a aula, foi percebido que a capacidade de sequenciar cronologicamente as atividades que fazíamos era de grande dificuldade para uma boa parte dos alunos, muitos ao serem perguntados como começou a aula, relatavam as práticas do final da aula, muitas vezes foi preciso organizar cronologicamente a sequência das práticas em conjunto com os alunos. Esse exercício que inicialmente foi feito para ser uma coleta de dados para a pesquisa, acabou ganhando força para se tornar uma atividade realizada nas demais aulas além da pesquisa, uma vez que a capacidade de sequenciação é fundamental para a prática musical e para diversos momentos da vida, auxiliando na capacidade de classificar, abstrair, generalizar e conceituar.

\section{Considerações finais}

Refletindo sobre o questionamento central da pesquisa de como a apreciação pode compor a prática pedagógica do docente que trabalha com jovens e adultos com diversidade funcional intelectual, respondemos que o referencial teórico escolhido, aliado a prática da pesquisa-ação demonstrou que a apreciação pode ser um elemento desencadeador do aprimoramento do fazer musical, através de recursos visuais como musicogramas e musicovigramas, proporcionando o reconhecimento das imagens e sons, sua organização espaço-temporal, a escuta e

BIONDO JÚNIOR, Edson Ribeiro; RAYMUNDO, Diewerson do Nascimento. Educação Musical no contexto de jovens e adultos com diversidade funcional intelectual: recursos de Apreciação Musical. Revista da FUNDARTE. Montenegro, p.01-21, ano 20, oㅡ 41, Abril/Junho de 2019.

Disponível em: http://.seer.fundarte.rs.gov.br/index.php/RevistadaFundarte/index> 30 de junho de 2020. 


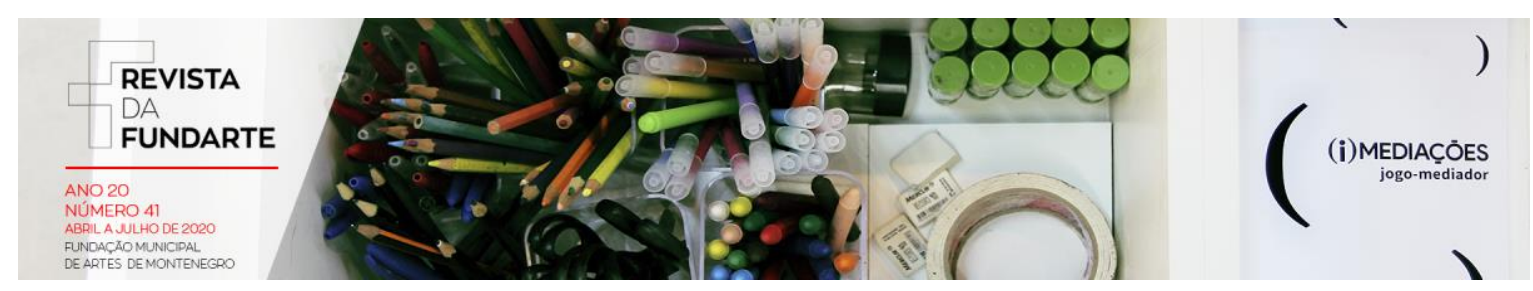

prática das músicas executadas através da percussão corporal e da execução instrumental, assim como a apreciação da mesma música em diversos arranjos, contribui para que esses elementos musicais fossem vivenciados pelo grupo.

A utilização dos musicogramas e musicovigramas, promoveram a capacidade de generalização, abstração e conceituação, o reconhecimento das partes do corpo e seu respectivo som na percussão corporal e a possibilidade de composição de sequência de sons por parte dos alunos.

Espera-se que essa prática possibilite novas pesquisas e experimentações sobre Educação Musical e Apreciação musical na educação de pessoas com diversidade funcional intelectual, possibilitando um modo mais humano e horizontalizado de educação que esteja de encontro às necessidades da escola e do grupo de alunos.

\section{Referências:}

BUENO, Silveira. Minidicionário da língua brasileira. São Paulo: FTD, 2001.

DÍAZ-POSADA, Leidy Evelyn; RODRÍGUEZ-BURGOS, Lilian Patricia. Educación inclusiva y diversidad funcional: Conociendo realidades, transformando paradigmas y aportando elementos para la práctica. Colômbia: Universidade do Norte. 2016; (24):43-60. ISSN: 1657-2416. Disponível em: <https://www.redalyc.org/articulo.oa?id=85346806005>. Acesso em: 15/01/2020

GREBORE, André Luiz. O Gesto Na Audição Ativa Do Método Orff/Wuytack. Anais. Simpósio de estética e filosofia da música - SEFiM/UFRGS. V.1, N.1.UFRGS: Porto Alegre, 2013.2 Disponível em: <http://www.ufrgs.br/sefim/ojs/index.php/sm/article/view/143/163>. Acesso em: 09/06/2019.

LOURO, Viviane. Educação musical e deficiência: quebrando os preconceitos. Site da autora. 2013a. Disponível em: <https://musicaeinclusao.files.wordpress.com/2013/06/educacao_musical_e_deficien cia_quebrando_os_preconceitos.pdf>. Último acesso em: 12/12/2018.

LOURO, Viviane. Fundamentos da aprendizagem musical da pessoa com deficiência. 1aㅡ ed. - São Paulo: Editora Som, 2012.

BIONDO JÚNIOR, Edson Ribeiro; RAYMUNDO, Diewerson do Nascimento. Educação Musical no contexto de jovens e adultos com diversidade funcional intelectual: recursos de Apreciação Musical. Revista da FUNDARTE. Montenegro, p.01-21, ano 20, oㅡ 41, Abril/Junho de 2019.

Disponível em: http://.seer.fundarte.rs.gov.br/index.php/RevistadaFundarte/index> 30 de junho de 2020. 




MORALES, D. S.; BELLOCHIO, C. R. A educação musical especial em produções dos Encontros Nacionais da ABEM. In: Congresso Nacional da Associação Brasileira de Educação Musical, 18ํe e Simpósio Paranaense De Educação Musical, 15ํㅡ, 2009, Londrina. Anais... Londrina: ABEM, 2009. p. 114-126

OLIVEIRA, Joílson Almeida de; OLIVEIRA, Pedro Augusto Dutra de. Musicogramas e musicovigramas: possibilidades de apreciações musicais na sala de aula. Educação, Batatais, V. 9, N. 2, p. 75-89, jan./jun. 2019.

PALACIOS, Agustina; ROMAÑACH, Javier. El modelo de la diversidad: la Bioética y los Derechos Humanos como herramienta para alcanzar la plena dignidad en la diversidad funcional. edra a oru a diciones iversitas- AIES, 2006.

PALHEIROS, Graça Boal. BOURSCHEIDT, Luís. JosWuytack- A pedagogia musical ativa. In: Pedagogias em educação musical. Teresa Mateiro, Beatriz llari (Org) Cutitiba: Intersaberes, 2012.

PEREIRA, Ray. Diversidade funcional: a diferença e o histórico modelo de homempadrão. História, Ciências, Saúde - Manguinhos, Rio de Janeiro, v.16, n.3, jul.-set. 2009, p.715-728.

ROMAÑACH, Javier; LOBATO, Manuel. Diversidad funcional, nuevo término para la lucha por la dignidad en la diversidad del ser humano. Foro de Vida Independiente, p. 1-8, 2005.

THIOLLENT, Michel. Metodologia da pesquisa-ação. 18ª̣ed. - São Paulo: Cortez, 2011.

TRIP. David. Pesquisa-ação: Uma introdução metodológica. Educação e Pesquisa, São Paulo, v. 31, n. 3, p. 443-466, set./dez. 2005.

WUYTACK, Jos. Palheiros, Graça Boal. Audición musical activaconelmusicograma. Eufonía. Didáctica de la Música. Logroño, La Rioja (Espanha) - num 47 - pp.43-55 julio 2009. Disponível em: <http://www.awpm.pt/docs/EufoniaMai09.pdf>. Acesso em: 16/07/2019.

BIONDO JÚNIOR, Edson Ribeiro; RAYMUNDO, Diewerson do Nascimento. Educação Musical no contexto de jovens e adultos com diversidade funcional intelectual: recursos de Apreciação Musical. Revista da FUNDARTE. Montenegro, p.01-21, ano 20, oㅡ 41, Abril/Junho de 2019.

Disponível em: http://.seer.fundarte.rs.gov.br/index.php/RevistadaFundarte/index> 30 de junho de 2020. 